\title{
Monitoring Progress Toward Fulfilling Rights in Early Childhood Under the Convention on the Rights of the Child to Improve Outcomes for Children and Families
}

Clyde Hertzman, Ziba Vaghri, and Adem

Arkadas-Thibert

\section{The Problem}

What happens to children in their earliest years is critical for their development throughout the life course. The years from birth to school age are foundational for brain and biological development. Attachment and face recognition, impulse control and regulation of physical aggression, executive function in the prefrontal cortex and focused attention, fine and gross motor functions and coordination, receptive and expressive language, and understandings of quantitative concepts are all established during this time and become embedded in the architecture and function of the brain. Brain and biological development are in turn expressed through three broad domains of development of the whole child: physical, social-emotional, and language-cognitive, which together form the basis of "developmental health." Developmental health influences many aspects of well-being, including obesity and stunting, mental health, heart disease, competence in literacy and numeracy, criminality, and economic participation throughout life. The problem explored in this chapter is: How can the United Nations (UN) Convention on the Rights of the Child (CRC) be used as a tool to support developmental health in the early years?

Children's human rights were made into legally binding international law with the CRC, through unanimous adoption by the UN General Assembly in 1989. The $\mathrm{CRC}$ is the human rights treaty that provides a firm legal basis for a comprehensive framework for early childhood, as well as international standards for fulfilment of children's rights in early years (See Chapter 4, this volume for a detailed description of the CRC). Its legal power is strengthened by the fact that it is the most widely agreed-upon international human rights treaty in the world, with 193 
signatory countries. However, signatory countries, although aware of the importance of early childhood, often overlook their obligations in the early years largely because of the perceived invisibility of very young children. Moreover, improving early child development requires finding ways for social determinants and child rights approaches to work together in common purpose. To date, this has not occurred.

\section{The Issues}

Economic and population health approaches have tended to focus on society's collective interest in the future of the child; that is, on early childhood contributions to their capacities as adults. Developing in parallel, the philosophy of human rights, as enshrined in the CRC, has led to a different approach. Rather than viewing the young child as a passive recipient of "interventions" to aid them on the way to becoming healthy, economically productive adults, it emphasizes the young child as a being with inherent human rights, in present time. Human rights discourse maintains that young children are holders of rights and should be respected for their inherent value as human beings, as well as for their skills and competencies. General Comment 7 ( $\left.\mathrm{GC}_{7}\right)$ was appended to the Convention in 2005. It focuses exclusively on children 0-8 years old; accordingly, that will be the age range considered in this chapter. It makes explicit young children's right to enjoy their childhood to the full; the right to have good health, to learn, and to play (UNCRC, 2005). Although the human rights approach might appear in conflict with economic and population health approaches, it is not. Birth cohort studies from around the world document experiences that violate children's rights in early childhood, showing how they damage developmental trajectories across the life course. Thus, if rights in early childhood are not respected, protected, and fulfilled in present time, children are unlikely to thrive and contribute socially and economically in future.

Despite the potential synergies, rights and population health cultures have generally been unaware of each other, appealing to different constituencies and missing opportunities for making common cause. Indeed, there have been tensions. For example, consider this statement about the Millennium Development Goals (MDGs), which are a paragon of the outcome orientation of population health, from a leading rights scholar "while an ideal version of the MDGs is certainly compatible [with human rights], a bare-bones version which is sometimes put forward might accord only a token role to civil and political rights and endorse a very limited portion of the overall economic, social and cultural rights agenda" (Alston, 2003). The central concern here is that rights holders be "active claimants of their rights, rather than passive beneficiaries of charitable works" (Levi, 2009). This active/passive distinction is important to acknowledge and transcend, because it is fair to claim that population health has, in fact, inadvertently conceived of the 
child in passive terms, emphasizing the role that societies should play in improving the intimate environments of stimulation, support, and nurturance on behalf of young children. Without a complementary human rights approach, emphasizing young children's right to active participation in their lives and legitimizing their de facto role in influencing the environments where they grow up, live, and learn, the population health approach amounts to reducing the child to a passive beneficiary of society's good works.

Placing the "rights environment," with its emphasis on active participation, on an equal footing with the population health approach, with its emphasis on environments of stimulation, support, and nurturance, transcends the active/passive dichotomy described above. The $\mathrm{CRC}$ and $\mathrm{GC}_{7}$ provide minimum legal standards for governments to observe in order to uphold the human dignity of young children but, also, these documents provide an impetus to act upon the fact that fulfilment of young children's rights requires special attention to their intimate, and broader socioeconomic, environments. In practice, this means that opportunities for survival, physical, and social-emotional and language-cognitive development for all young children are guaranteed in law, provided without discrimination, and implemented in ways that encourage young children to be active participants in their own lives.

\section{INEQUITY FROM THE START AS A RIGHTS VIOLATION:}

THE EXAMPLE OF CANADA

In Canada, population-based assessments of early child development are conducted during the transition year to formal schooling, at age 5, using the Early Development Instrument (EDI). The EDI allows each child to be scored as "vulnerable" or "not vulnerable" in his or her development (Janus et al., 2007) and, by the end of the $2007 / 08$ school year, EDIs had been done on approximately $80 \%$ of the age 5 Canadian population. These data revealed that $25 \%-30 \%$ of Canadian children were vulnerable in their development, ranging from a low of $4 \%$ in some communities to a high of $68 \%$ in others (Hertzman, 2009). Approximately half of this 17 -fold range is explained, statistically, by socioeconomic conditions, whereas the rest relates to parenting styles, community governance, and neighborhood access to quality programs and services for young children. Most important here, by conservative estimates, more than $60 \%$ of the vulnerability measured on the EDI could have been avoided if the children had had better quality experiences in their first 5 years. According to the World Health Organization (WHO) Commission on the Social Determinants of Health, this state of affairs would violate the principle of "equity from the start." Moreover, under $\mathrm{GC}_{7}$, it is possible to construe such high levels of avoidable vulnerability and inequality in early child development as a human rights issue. Although it is true that social justice is not just a rights issue, and rights are not just a social justice issue, there are very good strategic reasons to emphasize the overlap. As evidence continues to emerge, globally, on 
modifiable vulnerabilities in early child development (Grantham-McGregor et al., 2007), there will be an impetus to build coalitions between those with an equity orientation and those with a rights perspective, in order to deal from a position of strength in the policy arena for the benefit of young children. A bridging of approaches means that "equity from the start" is seen as the fulfilment of social justice, as a sound investment in health and human development, and, also, as the fulfilment of a basic human right.

\section{THE CASE FOR MONITORING THE IMPLEMENTATION OF CHILD}

\section{RIGHTS IN EARLY CHILDHOOD}

The CRC is the first comprehensive human rights legal instrument linking civil and political rights with economic, social, and cultural rights (ESCR). The right of a young child to develop, like the right to food, health, housing, family, education, and work, falls into the category of ESCR (Green, 2001), which are recognized, internationally, as "substantive" rights. Unlike "procedural" rights, such as the right to nondiscrimination, substantive rights are subject to the obligation of "progressive realization." What does this mean? Procedural rights always create an immediate duty on the state to be fulfilled at once, since they are amenable to direct control by responsible individuals. In contrast, substantive rights cannot be fulfilled overnight, because a wide range of societal conditions influence their fulfilment, and these conditions are not under the control of specific individuals who can be held directly responsible. International rights treaties recognize this by holding the state and other duty-bearers responsible for taking steps toward gradually, but incrementally achieving the realization of substantive rights over time (i.e., progressive realization). In other words, it is understood that the barriers to fulfilling the substantive rights in $\mathrm{GC}_{7}$ are deeply embedded in society, such that they will take considerable time and effort to remove (Green, 2001).

To achieve progressive realization of substantive rights, policies, programs, and practices must be consistent with the commitments governments have made to CRC, including general comments adopted under CRC article $45(\mathrm{~d})$. Once governments make this commitment, they are held accountable by periodically reporting on progress to the UN Committee on the Rights of the Child (herein, the Committee) (Khattab \& Arends, 2009). Reporting is essential in the case of commitments requiring progressive realization, since evidence of progress (or lack of it) may be diffuse, slow changing, and contested. In the case of rights in early childhood, progressive realization is largely bound up in the conditions of children's daily lives. Without active efforts at monitoring and reporting on these conditions, progressive realization would go unmonitored. Moreover, as things improve, what is expected of a state to fulfil its CRC obligations toward young children will increase over time. Accordingly, paragraph 39 of $\mathrm{GC}_{7}$ suggests that indicators and benchmarks should be used by "states parties" to monitor the realization of child rights in early childhood. The logic is straightforward: Child rights indicators for 
early childhood should derive from $\mathrm{GC}$, since it provides the normative framework for the indicators to monitor the implementation of CRC in early years, with a view to holding duty-bearers to account (Hunt, 2003).

In theory, indicators make it possible for people and organizations to identify important actors and hold them accountable for their actions; serve as tools for making better policies and monitoring progress; identifying unintended impacts of laws, policies, and practices; provide early warning of potential violations; enhance social consensus on difficult trade-offs that need to be made in the face of resource constraints; and identify when policy adjustments are required. (Hunt, 2003)

Already, there are many examples of indicators that have the capacity to monitor progress in early childhood care and development, such as the Early Development Instrument (Janus et al., 2007) and relevant modules of the Multiple Information Cluster Survey conducted in more than 40 countries by UNICEF (United Nations Department of Economic and Social Affairs [UN DESA], 2006) (although not yet on its companion, the Demographic Household Survey). This raises crucial questions. Do we need a new indicator framework based on young children's human rights? What is the added value of having rights-based indicators? In general, what is the relationship between population health/human development indicators in childhood, on the one hand, and child rights indicators, on the other? In answer to the last question, the former are oriented toward goals, usually defined in terms of survival and well-being, whereas the latter are usually a means of determining the extent to which a government is complying with its treaty obligations, whether or not they further human development goals (Green, 2001). Specifically, two main characteristics of child rights indicators are not typical of other childhood indicators:

1. They are based on international binding legal documents and measure not only the progress in the situation of children but also how governments, as duty-bearers, fare in fulfilling their legal obligations toward young children.

2. They do not just look at the progress made, but they identify gaps and missing capacities and ask further questions to understand discrepancies. Did the process leading to progress respect and protect young children's rights, including their right to be heard and to participate in the process in an equitable and non-discriminatory manner? Has the best interest of the young child been made the paramount consideration in the mechanisms? What measures have been taken to uphold the right to non-discrimination, including creating equality of opportunity and outcome?

Translating the diverse conditions of children's daily lives into measurable indicators requires an element of reductionism. Reductionism connotes loss of information, but there is a trade off with commensuration. Commensuration transforms qualities into quantities and difference into magnitude, and allows us to quickly grasp, represent, and compare differences. It offers a standardized way of constructing proxies for uncertain and elusive qualities and condenses and 
reduces the amount of information people have to process, thereby simplifying decision-making (Espeland \& Stevens, 1998). The monitoring protocol for GC7, described below, is designed to strike a feasible balance between reductionism and commensuration.

\section{A Theory of Change}

The environments where children grow up, live, and learn influence the quality of their early experiences, which, in turn, shape long-term outcomes (Irwin, Siddiqi, \& Hertzman, 2007). Environments and experiences that influence development range from the most intimate (i.e., moment-to-moment interactions in the family), to the societal (i.e., the influence on living conditions of the globalizing economy). The WHO's Commission on the Social Determinants of Health recognized these realities in its 2008 final report, "Closing the Gap in a Generation: Health Equity Through Action on the Social Determinants of Health" (Commission on Social Determinants of Health [CSDH], 2008). Chapter five of the report, called "Equity from the Start," was devoted to early child development from the perspective of population health. It called upon all 193 WHO member countries "commit to and implement a comprehensive approach to early life, building on existing child survival platforms and extending interventions in early life to include social/ emotional and language/cognitive development."

The CRC provides a monitoring mechanism for all signatory countries, placing a legal obligation on countries to write periodic reports to the Committee on the Rights of the Child as the monitoring body of the CRC. "The committee, as a part of their mandate under CRC article $45(\mathrm{~d})$, also issues "General Comments" to guide governments in better understanding, implementing, and monitoring the implementation of the $\mathrm{CRC}$ in their countries. One of these is GC7: Implementing Rights in Early Childhood. It was adopted in response to the observation by the Committee that children under the age of 8 years were often entirely overlooked in states parties' reporting of progress toward implementing CRC. GC7, adopted in 2005, reiterates that every child should enjoy a safe and nurturing childhood in which to develop and grow to his or her full potential, free from violence and want. Young children have the right to enjoy their childhood to the full, the right to have good health, to learn, and to play. Young children have the same rights and freedoms as all other children, but they are deemed to be particularly vulnerable due to their age and special developmental needs.

Because of the monitoring role of the committee, $\mathrm{GC}_{7}$ has also provided a timely opportunity for developing early childhood indicators based on human rights.

The theory of change, here, is that $\mathrm{GC}_{7}$ can be used as a tool for achieving equity from the start, if it is accompanied by a commitment to both corrective and distributive justice. Equity means reducing avoidable inequalities in early child development according to (for example) socioeconomic status, ethnicity, 
geography, and gender. These are aspects of distributive justice; that is, they are concerned with reducing the variance in the distribution of life chances facing young children (de Grieff, 2009). At the same time, concern with the distribution of life chances is not just about monitoring outcomes, but recognizing that children from different walks of life may face very different barriers to thriving, such that the correction of past inequities ultimately has an impact on future life chances. Thus, both corrective and distributive justice is necessary, and need to be made to support and reinforce one another. We believe that a human rights-based approach to early childhood development provides a legal basis for this to happen. For example, prohibition of discrimination is "customary law" (i.e., it is accepted by all countries as a norm, even if they are not a party to the specific human rights treaty at issue). Corrective and distributive justice is derived from well-established nondiscrimination and equality provisions in both domestic and international law. Accordingly, a human rights approach would assert that it is not enough to simply open the doors to a program or service that could assist in early development, such as quality child care, and say "everyone can come." Because children from different walks of life may experience very different de facto barriers of access (e.g., cost, transportation, language, social trust, stigmatization, etc.), attendance will differ, not necessarily according to who wants or could benefit from the service, but according to the range and intensity of barriers that stand between the child and the program. A rights-based approach dictates that these barriers must be addressed in order that children's rights not be violated (Kitching, 2005).

\section{A MONITORING PROTOCOL FOR GC7}

Support for the value of child rights indicators is provided by the startling fact that there is no consistent association between ratification of human-rights treaties and health or social outcomes (Palmer et al., 2009). Why aren't these treaties prepared with good intentions and a sound knowledge base conducive to improved rights status? One theory is that it is due to the lack of tools to monitor the progressive realization of social and economic rights, tools that are sensitive enough to detect and measure relevant change. Accordingly, development of such tools should be helpful in an environment of good faith. Where good faith fails, improved accountability mechanisms to monitor compliance of states with treaty obligations, and financial assistance to support the realization of the right, could be a part of the solution.

As one of the leading international nongovernmental organizations (NGOs) that helped develop $\mathrm{GC}_{7}$, the Bernard van Leer Foundation led a study to explore obstacles to its implementation, to evaluate how $\mathrm{GC}_{7}$ was being received by signatory countries, and to determine how the General Comments have been interpreted since 2005. One of the main components was a pilot study of $\mathrm{GC}_{7}$ in Jamaica, which attempted to evaluate, in situ, its value to experts and community members, and whether it allowed the voices of young children to be heard. ${ }^{2}$ 
Based upon this study and the work of the WHO Commission on the Social Determinants of Health in January 2006, the committee formally requested that an ad hoc group of researchers, WHO, UNICEF, and child rights advocates from several NGOs create a framework of indicators for GC7. The result was the Early Childhood Rights Indicators Group (hereinafter, the Group). The Group worked to create a framework of indicators that countries could use to assess their current rights environment, to monitor the implementation of rights in early childhood, and to facilitate reporting to the committee. This framework, completed in May 2008, specifically addressed the rights that are upheld in the CRC but elaborated in GC7. It also addressed the following underlying and cross-cutting themes: the need to recognize young children as rights holders and active social participants; countries' obligations to provide appropriate and adequate support for caregivers of young children; the need for integrated service provision in support of holistic approaches to child development; the need to support the evolving capacities of young children through positive education and health promotion, preschool, and play experiences; freedom from social exclusion by virtue of young age, gender, race, ethnicity, and disability; freedom from violence; and measures to increase understanding of the particular vulnerabilities of young children.

\section{ORGANIZATIONAL FRAMEWORK OF THE INDICATORS}

The framework includes 15 indicator sets that build on existing UNICEF and WHO indicators but proposes new configurations of administrative data to gauge the implementation and enjoyment of rights in early childhood. Indicators are arranged according to a hybrid model that combines elements of the structure of the CRC reporting guidelines (UNCRC, 2010), the format of UNICEF's Multiple Information Cluster Surveys, and the structure of the WHO's Right to Health framework.

To simultaneously promote rights in early childhood and pursue the goal of equity from the start, the Group had to finesse the distinction, made above, between human rights and population health approaches. As will be seen below, the Group's approach was to merge them, organizing indicators according to structure, process and, notably, outcome, congruent with the approach of the UN Office of High Commissioner for Human Rights (OHCHR, 2008).

The indicator sets proposed in the framework are organized according to the CRC Reporting Guidelines (UNCRC, 1991). Under each cluster heading, a rationale for the indicator sets provides appropriate references to relevant articles in the $\mathrm{CRC}$ and paragraphs of $\mathrm{GC}_{7}$. Next, an overarching question is presented that provides easy understanding of the purpose of each indicator. These are then unpacked into sets of questions that are divided into sections titled Structure, Process, and Outcome (Appendix I; Figure 19.1). Structure, as an indication of commitment, refers to the existence of institutions and policies aligned with the CRC to realize the particular right in question. Process refers to efforts made and actions taken to 
fulfil the commitment, and thus to specific activities, resources, and initiatives in pursuit of rights realization. Outcome refers to a resultant and measurable change either in the "rights environment" or directly in the status of young children's development. Within these tables, we also identify potential sources of information, specify the relevant duty bearers, and provide references to sections of the reporting guidelines (Vaghri et al., 2009).

The indicator framework is not only a tool for governments to fulfil their obligation for periodic reporting to the committee, it is also meant to be an efficient institutional self-assessment tool and an inventory check list to help governments become aware of what policies, programs, and outcome information are (or are not) already available across a wide range of ministries, Non-Governmental Organizations (NGOs), and localities. Each indicator set contains a flow chart (Appendix II) that is meant to be the focal point for evaluation. It walks the report writer(s) through a series of questions regarding existing policies and programs, then moves to explore outcomes. In cases where a country's answer to a given policy/program question is negative, the flow chart provides examples of model policies/programs from countries across the globe. A conscious attempt has been made to include as many examples from the resource-poor countries as possible, often followed by website addresses or additional information. Upon completion of the indicators, governments should have a clear idea about the existing gaps in their systems, thus giving them a head start in filling in these gaps.

The contextual relevance of indicators is a key consideration in their acceptability and use. Countries often differ in terms of their level of development and realization of human rights. As a result of these differences and the nature of institutions, the policies and the priorities of states may differ. Therefore, it is not always possible to create indicators for child rights that are strictly universal. The $\mathrm{GC} 7$ Indicators Group kept this in mind and left open the possibility that there might be a need to customize certain parts of the indicator sets. Moreover, in May 2008, upon presentation of the framework to the committee, although a strong letter of support was sent to the GC7 Indicators Group, the committee articulated that it:

[W] elcomes the plans to finalize this project so that a set of broadly applicable indicators regarding the implementation of rights of young children becomes available. The next steps have to be pilot studies in order to test and revise the list of indicators if necessary. (Dr. Yanghee Lee, UNCRC)

\section{Summary of Evidence}

In accordance with this directive from Dr. Lee, pilot implementations have been taking place in selected countries. Starting in Tanzania, the piloting protocol unfolded in a planned sequence: feasibility assessment, gathering stakeholders 
in a roundtable setting, identifying the country taskforce, training the taskforce in workshop format, face-validation of the indicators, data collection, mid-term evaluation, data review upon completion, interpretation, and wrap-up feedback meeting with all stakeholders and participants. Each event was designed to help build a community of understanding among the $\mathrm{GC}_{7}$ Indicators' project team, the country taskforce, and the stakeholders. Data were summarized, tabulated, and interpreted by the project secretariat during the data review and analysis phase, allowing it to identify the areas of the implementation manual that needed improvement. It also provided a basis for summary feedback to Tanzania about its existing capacities and gaps within its policies and programs and its outcome information.

Piloting the GC7 Indicator Framework has been an essential step toward building an internationally credible child rights monitoring tool. In addition to helping identify areas of confusion and ambiguity in the manual and indicators, the pilot helped the Group identify practical problems, such as the need for an electronic system for responding to the indicators that would be feasible in low-, middle-, and high-income countries. This would not only reduce the time required to create countries' periodic reports, but could also improve the efficiency of reporting to the committee.

The Group also learned that, although quantification simplified reporting, the qualitative aspect remained indispensable. When an attempt is made to quantify and compare a country's capacities regarding a given right, the transformation of country-specific knowledge into numerical representations does, indeed, strip meaning and context from the phenomena. Without any information on outcomes, a scarcity of policies and programs might be interpreted as limited capacity in the country, whereas in reality it may be due to the efficiency and effectiveness of the limited number of existing policies and programs, which has eliminated need for anything further. For example, in Tanzania, birth registration is one of the least fulfilled among child rights, with a birth certification rate among the lowest in Sub-Saharan Africa at less than 8\% (Cody, 2009). The limited number of policies and programs regarding this right (indicator 5 ) is, in this case, indicative of limited capacity. However, in the absence of outcome data, one could not reach such a conclusion. In contrast, the right to education is probably one of the best attended. Tanzania has one of the highest literacy rates in Africa, reaching $98 \%$ by the mid-1980s and with preprimary enrollment rates experiencing a steady increase throughout the 1990 (Sitta, 2007). The number of policies and programs reported for indicator $\mathbf{1 1}$ "the right for early education services" are also limited and comparable to the numbers reported for indicator 5 , the right to birth registration. In the absence of outcome indicators, these two rights could be mistakenly put in the same category, the category of severely unfulfilled rights, whereas the outcome data tell a very different story.

Data collection is somewhat constrained everywhere. Although the most obvious reason for this is usually cost, Davis et al. (2010) have argued that sometimes 
the concerns about what data could reveal is the underlying reason for it being missing. For example, a UN study found that, in 2005, only 59 countries (or subnational regions) had reported the total number of households, based on census sources, and only 42 disaggregated these figures by sex and age of the head of the household (UN DESA, 2006, pp. 13, 18-19). Information on the number of first marriages, according to the age of the bride and groom, was stated by only 85 countries (or regions), representing $27 \%$ of the world's population. None of the 50 least developed countries provided these data to the UN (UN DESA, 2006, pp. 11, 18-19). Although data collection capacity is likely one reason for this, an unwillingness to open a discussion on child marriage is undoubtedly another. In any case, the data deficit inhibits evaluating the extent of child marriage worldwide.

Irrespective of these obstacles, progressive realization of rights in early childhood demands better information flows. The components of an efficient system include regular data collection and a well-organized and transparent archiving system that facilitates data retrieval and minimizes redundancy. Such a system should facilitate data linkage, which itself can promote intersectoral and multilevel approaches. Data retrieval appeared to be one of the main challenges in our first pilot. Many government officials were certain about the existence of specific data but had considerable problems retrieving it. In Tanzania, the retrieval problem seemed to be due to two factors: a disorganized, paper-based system for managing written legislation, policies, and outcome reporting, and, also, the well-known tendency, common in governments across the world, of shelving and forgetting about things that are difficult to implement.

An ironic aspect of the Tanzanian pilot was that the justice system was virtually absent from the process. Since the core aspects of Rights in Early Childhood are substantive, rather than procedural, they fell under ministries of health, education, and community/gender, rather than justice. Yet, the lack of involvement of the putative "enforcing" ministry was notable. It will be important to see if this pattern plays out in other pilot countries.

Finally, the Group found virtually no familiarity with $\mathrm{GC}_{7}$ among the government officials of our first pilot country. Conducting the pilot not only introduced the indicators of $\mathrm{GC}_{7}$, but also $\mathrm{GC}_{7}$ itself. It is our belief that, paradoxically, a country's willingness to implement the indicators will serve as a method of consciousness-raising for the very existence of GC7.

The Tanzanian experience showed that there were two distinct aspects to piloting: the technical and the human. Whereas the technical aspect represented an opportunity for a thorough inventory of the country's capacities for implementing child rights, the human aspect created opportunities to improve inter- and intraministerial communication. It also engaged some vital players who traditionally went underrepresented in the process of preparing CRC reports. At this point, the Group is not in a position to state which of the challenges, noted above, are country specific and which are common to countries across the globe. The next pilot, in Chile, may help sort this out. 


\section{Conclusion}

There are two overarching conclusions that emerge from this paper, which are also its leading policy implications.

1. There needs to be a commitment from the UN-CRC Monitoring Committee and key relevant international agencies (WHO, UNICEF) to a long-term program of monitoring compliance with $\mathrm{GC}_{7}$ in conjunction with monitoring of early child developmental outcomes, in all signatory countries, in order to ensure progressive realization of rights in early childhood and equity from the start.

2. Within states, the process of data collection must be part of a program of interministerial cooperation with government and intersectoral collaboration at the local level, thus raising the profile of the early years and increasing buy-in for taking action at all levels of society. Academic and civil society partners are indispensable for guaranteeing the integrity, validity, and transparency of this work as it spreads around the world and, also, over the long-term.

Implementing the monitoring protocol for rights in early childhood will only be worthwhile if, over time, it contributes to fulfilment of rights, improved quality of life, and enhanced developmental outcomes for young children. Thus, its ultimate value can only be evaluated over a time horizon measured in years. To this end, our strategy is to find ways to use the process and outputs of implementing the monitoring protocol as an anchor for a range of diffusion and social change processes. These include:

- Implementing the monitoring protocol, per se, is a tool to create new interministerial "policy coalition" among those who were brought together from different ministries to do the work. The unifying focus of this latent policy coalition is the range of duties that the state has to young children. If it gains influence over time, the policy research literature gives us reason to believe that evidence-based social change may result (Jenkins-Smith \& Sabatier, 1994). In practice, this would take the form of using the indicators as a guide for making better policies; creating a willingness to identify negative impacts on young children of existing laws, policies and practices; and reducing the prospects that children will be on the short end of policy trade-offs that are made in the face of resource constraints. Our approach to country feedback recognizes this coalition-building process and gives it a boost toward sustainability.

- Although most of the world's legal systems are much more attentive to procedural than substantive rights, the monitoring protocol, if it is implemented conscientiously, will generate trend data over place and time and 
among vulnerable population groups that will be usable to make claims, through legal as well as political channels, of violation of substantive rights. Already, in countries with children's commissioners, a process of legal claims making is emerging with respect to substantive rights.

- Since the items in the monitoring protocol are fixed and known in advance, they create a "level playing field" for community and civil society groups whose job it is to hold governments accountable for their duties to young children.

Domestically, there is a principle that "what gets counted, counts." In other words, the information flows per se should raise the profile of young children's issues, put evidence in the hands of those who work with young children, and improve the quality of public discussion about young children's issues. Internationally, the Committee on the Rights of the Child encourages civil society alternate reporting as part of its monitoring process. Working with a predictable set of indicators should make the job of alternate reporting much more effective than previously, when states parties were allowed to send the committee non-protocol-based, open-ended reports that concealed more than they revealed. Under those circumstances, alternate reporting was mostly about hunting for concealment in the official reports. With measured indicators, reported in a predictable way, alternate reporting has a better chance to focus on barriers to progress, which is where the focus ought to be.

\section{RESEARCH AND POLICY QUESTIONS FOR THE FUTURE}

- Can implementation of the monitoring protocol be shown to contribute to improvement in young children's outcomes over time? What are the differing methodological challenges to studying this question in low-, middle-, and high-income countries?

- Can policy coalitions based upon compliance with rights in early childhood be sustained over time? If the answer is "yes in some countries and no in others," then what are the country factors that matter?

- How do we measure the effectiveness of policy coalitions for young children?

- Can the bridge that we have built between population health and rights cultures be sustained at the international level, such that the efforts of these diverse groups can have a cumulative positive effect on young children over time?

- Can rights in early childhood be effectively brought to failed states through direct collaboration with local and regional actors? 


\section{Notes}

1. Articles $43-45$ of the UNCRC.

2. The final report of this work has never been published. Accordingly, the lessons learned from it came in the form of personal communications from Lothar Krappmann and Alan Kikuchi White, who were leaders of the study.

\section{References}

Alston, P. (2003). A human rights perspective on the Millennium Development Goals. Paper prepared for the Millennium Project Task Force on Poverty and Economic Development. New York: NYU Law School, Center for Human Rights and Global Justice.

Cody, C. (2009). Count every child: The right to birth registration. Woking, UK: Plan Ltd.

Commission on Social Determinants of Health (CSDH). (2008). Closing the gap in a generation: Health equity through action on the social determinants of health. Final Report of the Commission on Social Determinants of Health. Geneva: World Health Organization.

Davis, K. E., Kingsbury, B., \& Merry, S. E. (2010). Indicators as a technology of global governance (NYU Law and Economics Research Paper No. 10-13). NYU School of Law, Public Law Research Paper No. 10-26. Retrieved from http://ssrn.com/abstract $=1583431$

de Greiff, P. (2009). Articulating the links between transitional justice and development: Justice and social integration. In P. de Grieff \& R. Duthie (Eds.), Transitional justice and development (pp. 41-42). New York: Social Science Research Council.

Espeland W. N., \& Stevens M. L. (1998). Commensuration as a social process. Annual Review of Sociology, 24, 313-343.

Grantham-McGregor, S., Cheung, Y. B., Cueto, S., Glewwe, P., Richter, L., Strupp, B., et al. (2007). Developmental potential in the first 5 years for children in developing countries. The Lancet, 369(9555), 60-70.

Green, M. (2001). What we talk about when we talk about indicators: Current approaches to human rights measurement. Human Rights Quarterly, 23, 1062-1097.

Hertzman, C. (2009). The state of child development in Canada: Are we moving towards, or away from, equity from the start? Paediatric and Child Health, 14(10), 673-676.

Hunt, P. (2003). WHO workshop on indicators for the right to health. UN Special Rapporteur on the right to health. Washington, DC: World Health Organization.

Irwin, L., Siddiqi, A., \& Hertzman C. (2007). Early child development: A powerful equalizer. Report to the WHO International Commission on the Social Determinants of Health. Retrieved from http://www.earlylearning.ubc.ca/globalknowledgehub/documents/ WHO_ECD_Final_Report.pdf

Janus, M., Brinkman, S., Duku, E., \& Hertzman, C., Santos, R., Sayers, M., et al. (2007). The early development instrument: A population-based measure for communities. A handbook on development, properties and use. Hamilton, ON: Offord Centre for Child Studies, McMaster University. Retrieved from http://www.offordcentre.com/readiness/pubs/ publications.html

Jenkins-Smith, C. H., \& Sabatier, P. A. (1994). Evaluating the advocacy coalition framework. Journal of Public Policy, 14, 175-203. 
Khattab, M., \& Arends, D. (2009). EGRI for children: Foundations for an Egypt Child Rights Index as instrument for evidence-based child-friendly public policies. Egypt: UNICEF Egypt and National Council for Childhood and Motherhood.

Kitching, K. (Ed.). (2005). Non-discrimination in international law: A handbook for practitioners. London: The International Centre for the Legal Protection of Human Rights (INTERIGHTS).

Levi, R. (2009). Memos to the Successful Societies program. Toronto: Canadian Institute for Advanced Research.

Palmer, A., Tomkinson, J., Phung, C., Ford, N., Joffres, M., Fernandes, K., et al. (2009). Does ratification of human rights treaties have effects on population health? The Lancet, 373(6), 1987-1992.

Sitta, M. S. (2007). Towards universal primary education: The experience of Tanzania. UN Chronicle, New York: United Nations. Available at http://www.un.org/Pubs/chronicle/2007/issue 4/0407p40.html

UNCRC. (2005). Implementing child rights in early childhood (General Comment No. 7). [Online]. Retrieved from http://www2.ohchr.org/english/bodies/crc/docs/Advance Versions/GeneralComment7Rev1.pdf [5 January 2010]

UNCRC. (2010). CRC Treaty specific reporting guidelines, harmonized according to the common core document (CRC/C/58/Rev.2). Retrieved from http://www2.ohchr.org/english/ bodies/crc/docs/treaty_specific_guidelines_2010.doc

UNCRC. (1991). General guidelines regarding the form and content of initial reports to be submitted by State Parties under article 44, paragraph $1($ a) of the Convention. New York: United Nations.

United Nations Department of Economic and Social Affairs (UN DESA). (2006). The world's women 2005: Progress in statistics. New York: United Nations.

United Nations Office of High Commissioner for Human Rights (OHCHR). (2008). Report on indicators for promoting and monitoring the implementation of human rights. Seventh Inter-Committee Meeting of the Human Rights Treaty Bodies.

Vaghri, Z., Arkadas, A., Hertzman, E., \& Hertzman, C. (2009). Manual on implementing Early Childhood Rights Indicators Framework. Retrieved from http://content.yudu. com/Library/Aınitv/ChildRightsIndicator/ 


\section{Appendices}

\section{Appendix I: Unpacking the Indicators}

\begin{tabular}{|c|c|c|}
\hline \multicolumn{3}{|c|}{$\begin{array}{l}\text { Indicator Set 12: Educational Provision for Vulnerable Young Children } \\
\text { (CRC Articles 2, } 28 \text { and 29; General Conment 1: Aims of Education; General Comment 6: Trentment of } \\
\text { Unaccompanied and Separated Children Outside Their Country of Origin; General Comment 9: The Rights of } \\
\text { Ohildren with Disabilities; General Comment 10: Children's Rights in Juvenile Justice) }\end{array}$} \\
\hline Structure & \multicolumn{2}{|c|}{$\begin{array}{l}\text { - What policy commitments exist in your country to ensure equitable access to appropriate } \\
\text { quality early childhood education for vulnerable populations? } \\
\text { Does policy in your country include a commitment to research the underlying factors of } \\
\text { vulnerability, address direct exclusion, provide redress, and challenge the root causes of such } \\
\text { exclusion? } \\
\text { Does policy make sufficient provision to inform parents/caregivers and children in vulnerable } \\
\text { groups about their rights with regards to educational opportunities for their young children? }\end{array}$} \\
\hline Process & \multicolumn{2}{|c|}{$\begin{array}{l}\text { - Are there efforts in place to initiate or support programs and provisions that promote } \\
\text { inclusive education and the participation of children from all vulnerable groups in mainstream } \\
\text { education? } \\
\text { Are there efforts in place to introduce programs and/or initiatives that provide specific } \\
\text { educational opportunities to vulnerable groups where mainstream service provision is lacking } \\
\text { or unavailable? } \\
\text { Has the existing data on the provision of education been reviewed and disaggregated by } \\
\text { school attendance and different criteria of vulnerability? } \\
\text { Are there awareness-raising initiatives that promote understanding of children who are } \\
\text { excluded and initiatives that seek to address the root causes of the exclusion? } \\
\text { Have there been any government publications or distribution of other information resources } \\
\text { provided to the State party on the educational rights of vulnerable children and families? }\end{array}$} \\
\hline Outcome & \multicolumn{2}{|c|}{$\begin{array}{l}\text { - Has there been an increase in the number and/or proportion of young children from vulnerable } \\
\text { groups who have been included in mainstream or appropriate specialist education systems, for } \\
\text { the past five years? } \\
\text { Has there been an improved understanding of the specific circumstances of exclusion and its } \\
\text { root causes and prevention that have been demonstrated through specific mechanism, such as, } \\
\text { policy development, public awareness, judicial measures and proceedings? }\end{array}$} \\
\hline $\begin{array}{l}\text { Sources of } \\
\text { Information }\end{array}$ & \multicolumn{2}{|c|}{$\begin{array}{l}\text { Desk review of policy and measures to ensure inclusive mainstream access for vulnerable } \\
\text { groups or specific measures targeted to vulnerable groups } \\
\text { - School attendance ratios-general population vs. vulnerable groups } \\
\text { Populations/household surveys questions on pre-primary and primary school attendance; } \\
\text { home-based provisions }\end{array}$} \\
\hline Duty Bearers & \multicolumn{2}{|c|}{$\begin{array}{l}\text { - National and local government departments responsible for educational provision and also } \\
\text { justice and equality } \\
\text { - Civil society and private-sector providers of educational services for young children } \\
\text { - Professional teaching associations and other relevant professional bodies } \\
\text { - Social care service providers across all sectors: public, private and non-governmental } \\
\text { Parents, other caregivers and professional and/or lay bodies representing or supporting } \\
\text { and/or informing these stakeholders }\end{array}$} \\
\hline \multicolumn{2}{|c|}{ General Comment 7 (paragraphs) } & Reprorting Guidelines (sections) \\
\hline \multicolumn{2}{|c|}{$\begin{array}{l}3: \text { young child as rights holder } \\
24: \text { monitor and evaluate access and use } \\
36 \text { : vulnerable groups }\end{array}$} & $\begin{array}{l}6 \mathrm{~b}: \text { programs } \\
6 \mathrm{c}: \text { resources } \\
6 \mathrm{~d}: \text { statistical data } \\
34 \mathrm{a}: \text { education, training, guidance } \\
34 \mathrm{~b}: \text { aims and quality of education } \\
34 \mathrm{c}: \text { rest, leisure, culture (play also) } \\
35: \text { excluded groups } \\
36 \text { : organizational co-operation }\end{array}$ \\
\hline
\end{tabular}

FIGURE 19.1 Indicator Set 12

Source:Vaghri, Z., Arkadas, A., Hertzman, E., \& Hertzman, C. (2009). Manual on implementing Early Childhood Rights Indicators Framework. Retrieved from http://content.yudu.com/Library/A1nitv/ChildRightsIndicator/ 


\section{Appendix II: An Example Flow Chart}

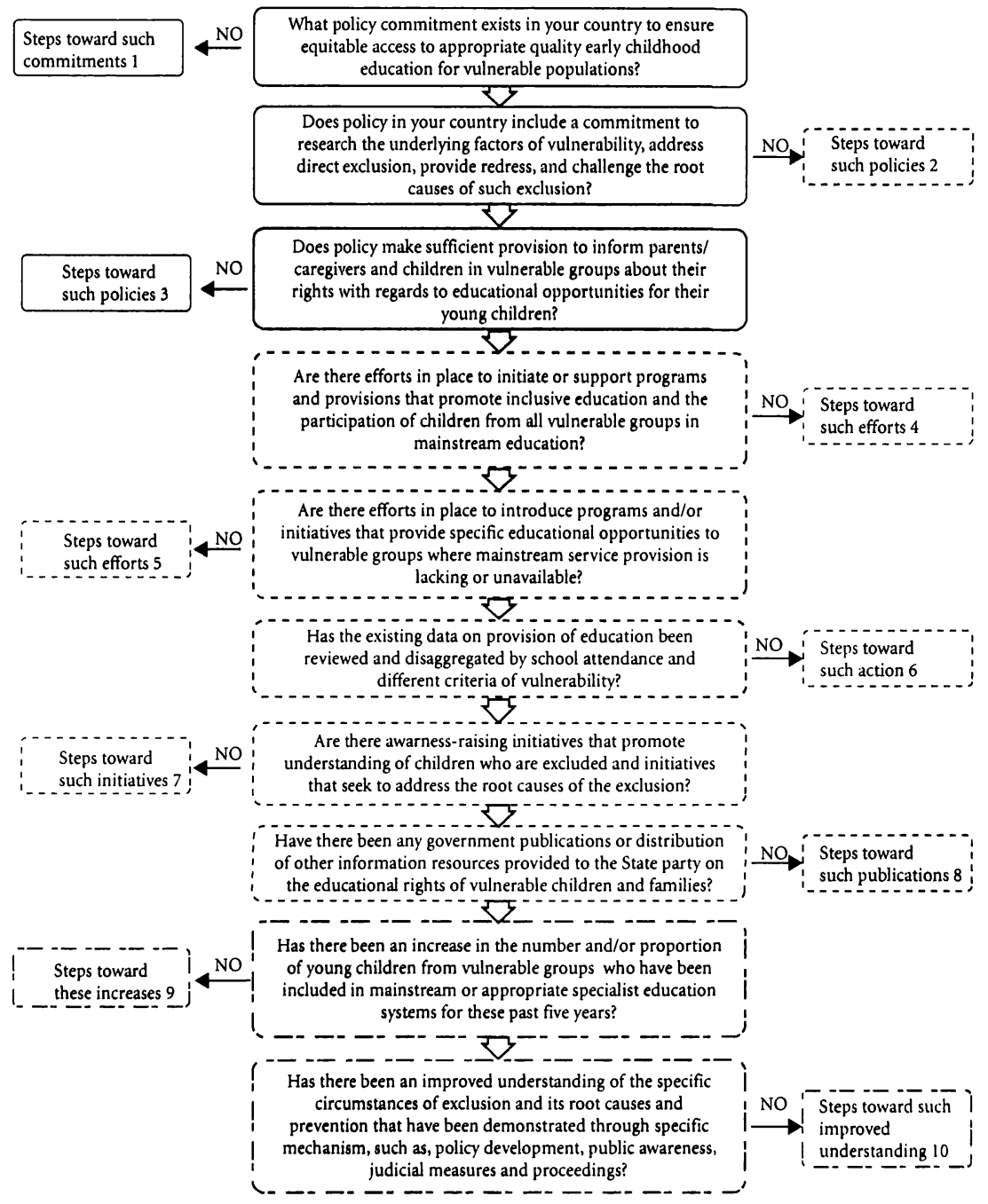

FIGURE 19.2 Schematic presentation of some steps to take to verify the presence of structure (—_ process (__ ), and outcome (__ for indicator 12, Realization of Educational Services Provision for Vulnerable and Excluded Young Children.

Source:Vaghri, Z., Arkadas, A., Hertzman, E., \& Hertzman, C. (2009). Manual on implementing Early Childhood Rights Indicators Framework. Retrieved from http://content.yudu.com/Library/Aınitv/ChildRightsIndicator/ 
Suggestions for Indicator 12

1. Develop policies that support social inclusion and insure equitable access to education, such as policies that

a. abolish school fees

b. provide income support to poor and rural households to reduce reliance on child labour

c. promote teaching in children's mother tongue

d. promote educational opportunities for disabled children and children affected by HIV/AIDS

For example, see the European Union National Strategy reports for social protection and social inclusion:

http://ec.europa.eu/employment social/spsi/strategy reports en.htm

2. Develop policies that support a commitment to research. The Encyclopedia of Early Childhood Developme nt website provides multiple examples of international research initiatives: http://www.child-encyclopedia.com/en-ca/recherche.html?q=research.

3. Expand on policies that make provisions to inform parents and children from vulnerable or excluded populations about their rights with regard to educational opportunity. For example, educational quotas for children from vulnerable or excluded populations, such as First Nation, Aborigine, Roma children in Europe, children living with disabilities, and so on.

4. Advocate for programs that encourage inclusive education and participation of children from all vulnerable groups in mainstream education. The National Inclusive Education Awareness ca mpaign in Canada website offer examples of multiple awareness -raising initiatives: http://www.inclusiveeducation.ca.

5. Encourage and implement programs that provide specific educational opportunities to vulnerable groups. For examples on educational programmes for vulnerable populations, see:

UNICEF Educational Priority Areas project:

http://www.unicef.org/romania/education 1617.html

Aga Khan Foundation Madrasa Early Childhood Education Programme:

http://partnershipsinaction.org/work/focus education.php

Public Health Agency of Canada's Aboriginal Head Start Program: http://www.phacaspc.gc.ca/dca -dea/programs-mes/ahs_main-eng.php

6. Work with university-based researchers and data managers to improve data resources.

7. Create awareness -raising campaigns, for example the "Leave No Child Out"Campaign: http://www.unicef.org/ceecis/kids_6643.html.

8. Work with WHO and UNICEF offices in your country to develop publications, translate relevant information into suitable languages, as well as carry out research from within your country to publish information on educational rights for vulnerable children and families. Valuable readings include:

A Human Rights Based Approach to Education for All:

http://www.unicef.org/publications/files/A_Human_Rights_Based_Approach_to_Education _for_All.pdf

Poverty Reduction Begins With Children:

http://www.unicef.org/publications/files/pub_poverty reduction en.pdf

9. Create a monitoring and evaluation system based on existing int ernational studies.

10. Explore the lack of improvement through, evaluation of policies, judicial measures and proceedings, and also conduct focus groups or investigate by using questionnaires.

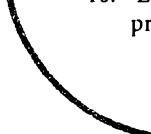

FIGURE 19.3 Suggestions for Indicator 12 